\title{
Development of Korean Version of Profile of Hearing Aid Benefit
}

\author{
Taehwa Kim¹,2, Songyong Sim³ ${ }^{3}$ Kyoungwon Lee ${ }^{2}$ \\ ${ }^{1}$ Busan Hanmi Hearing Aid Center, Busan, Korea \\ ${ }^{2}$ Department of Audiology, Hallym University of Graduate Studies, Seoul, Korea \\ ${ }^{3}$ Department of Statistics, Hallym University, Chuncheon, Korea \\ 한국어판 보청기이득평가 설문지 개발 \\ 김태화 ${ }^{1,2} \cdot$ 심송용 ${ }^{3} \cdot$ 이경원 $^{2}$ \\ 부산한미보청기난청센터 ${ }^{1}$, 한림국제대학원대학교 청각학과 ${ }^{2}$, 한림대학교 금융통계정보학과 ${ }^{3}$
}

\begin{abstract}
Purpose: The purpose of this study was to develop a questionnaire to assess gain of wearing hearing aid and to verify its reliability and validity. Methods: A total of 141 (average age: 65.7) hearing-impaired listeners participated in a survey for selection of items and 24 (average age: 72.67) hearing aid wearers participated in test-retest reliability test. In order to verify reliability and validity of Korean version-Profile of Hearing Aid Benefit (K-PHAB), factor analysis, Cronbach's alpha, a test-retest reliability (paired t-test, Pearson correlation coefficient), and $95 \%$ prediction interval were applied. Results: The results of this study were as below: 1) K-PHAB which was constructed through factor analysis after questionnaire survey on the selection of items was composed of ease of communication, background noise, reverberation, aversiveness of sounds and localization with a total of 20 items, 2) the result of factor analysis showed good construct validity, 3) the Cronbach's alpha coefficient appeared to be $0.75-0.81$, showing a high level of reliability, 4) the testretest correlation coefficient had high values such as $0.82-0.96,5) 95 \%$ prediction interval for each category was ranged from \pm 9.78 to \pm 13.78 . Conclusion: $K-P H A B$ had good reliability and validity, and could be used to measure the wearing effect of a hearing aid subjectively and specifically upon auditory rehabilitation of hearing aid wearers.
\end{abstract}

Key Words: Hearing aid, Hearing aid benefit, Self questionnaire, Abbreviated Profile of Hearing Aid Benefit, Korean Version of Profile of Hearing Aid Benefit.

Received: August 2, 2016 / Revised: September 23, 2016 / Accepted: October 7, 2016

Correspondence: Kyoungwon Lee, Department of Audiology, Hallym University of Graduate Studies, 405 Yeoksam-ro, Gangnam-gu, Seoul 06198, Korea Tel: +82-2-2051-4951 / Fax: +82-2-3453-6618 / E-mail: leekw@hallym.ac.kr

\section{INTRODUCTION}

난청인이 보청기를 착용한 후 보청기적합으로 인해서 발생하 는 음향 및 심리적인 이득을 측정하는 것은 중요하다. 보청기적 합 효과의 측정 내용은 보청기 착용 전후의 수행능력, 음향적 및 심리사회적 이득, 만족도, 핸디캡 등이 있으며, 객관적 또는 주관적인 평가 방법을 통해 측정할 수 있다.

Vestergaard(2006)에 따르면 보청기적합의 객관적인 평가는 보청기의 증폭과 기술적인 특성에 의해 제공하는 음향적인 이 득을 측정하며, 주관적인 평가는 청능재활의 전체 과정을 평가 할 수 있는 잠재력을 가지고 있다고 하였다. 객관적인 보청기적 합의 평가는 보청기 착용 전후의 청력역치의 차이를 구하는 기 능이득(functional gain), 조용한 곳 또는 소음 상황에서 어음 에 대한 이득, 커플러이득, 실이삽입이득, 방향이득 등으로 이 득, 최대출력, 방향성 등의 적절성을 확인한다. 하지만 객관적인 평가는 보청기센터 내에서의 효과를 측정한 결과이므로 실생 활에서 보청기의 착용으로 인한 효과로 보기에는 부족함이 있 다. Bentler et al.(1993)과 Cox \& Alexander(1992)는 설문조사 를 통한 보고와 보청기센터에서 측정한 어음인지 능력은 상관 관계가 약하게 나타났다고 보고하였는데 이러한 이유로 Goff (2013)는 청능재활 효과의 평가 시 객관적인 평가뿐만 아니라 주관적 평가도 함께 실시하여야 한다고 하였다. 주관적인 보청 기 착용의 효과는 일대일의 인터뷰 방식을 통해서도 측정할 수 도 있으나, 시간상의 문제와 현실성을 고려했을 때 설문지를 사 
용하여 측정하는 것이 일반적이다. 현재 설문에 답을 하는 자 가평가 설문지(self questionnaire)의 중요성은 널리 인식되어 있으며(Chang et al., 2014; Chu et al., 2012; Cox et al., 2003), 국내외에서 보청기적합의 효과를 평가하기 위한 다양한 설문 도구가 개발되어 있다(Chu et al., 2012; Cox \& Alexander, 1999; Ku \& Kim, 2000).

설문지는 주로 보청기 착용으로 인한 핸디캡 또는 만족도의 변화 그리고 심리음향적인 이득 또는 수행능력으로 평가하는 것으로 구분할 수 있다. 핸디캡 또는 만족도의 변화를 측정 시 사용되는 설문지로는 Korean version of International Outcome Inventory for Hearing Aids (Chu et al., 2012), The Korean Hearing Handicap Inventory for the Elderly (Ku \& Kim, 2000), Satisfaction with Amplification in Daily Life (Cox \& Alexander, 1999) 등이 있으며, 심리음향적인 이득 또는 수행 능력을 평가할 수 있는 설문지로는 Hearing Aid Performance Inventory (Walden et al., 1984), Glasgow Hearing Aid Benefit Profile (Gatehouse, 1999), Profile of Hearing Aid Benefit (PHAB) (Cox et al., 1991), Abbreviated Profile of Hearing Aid Benefit (APHAB) (Cox \& Alexander, 1995) 등이 개발되 어 있다. 이 중에서 $\mathrm{APHAB}$ 는 $\mathrm{PHAB}$ 를 축약한 것으로 '쉬운 의사소통(ease of communication, EC)', '소음(background noise, BN)', '반향(reverberation, RV)', '크고 날카로운 음 (aversiveness of sounds, AV)'의 4가지 항목에 대한 심리음향 적인 이득을 평가할 수 있도록 구성되어 있다. 각 항목은 6개씩 총 24개의 설문으로 구성되어 있으며, 반응 척도는 7 단계로 구 분되어 있다.

$\mathrm{APHAB}$ 는 $\mathrm{EC}, \mathrm{BN}, \mathrm{RV}, \mathrm{AV}$ 의 네 가지 항목에 대하여 평가 할 수 있도록 구성되어 있으나 난청인에게는 다양한 상황에서 의 어음을 인지하는 능력 외에도 음원의 위치를 지각하는 능 력 또한 중요하다. Lee \& $\operatorname{Lim}(2008)$ 의 보고에 의하면 난청인 은 소음이 있는 상황에서 의사소통의 어려움을 느낄 뿐만 아니 라 음원의 위치를 파악하는 능력에서도 건청인에 비해 저하된 다고 하였다. Noble et al.(1995)의 연구에서는 다양한 환경에서 소리의 방향 지각과 관련한 설문을 실시하였을 때 청력역치가 증가할수록 소리의 방향 지각에서 어려움을 보인다고 하였다. 이외에도 난청인의 방향지각 능력과 관련된 연구는 다양하게 이루어졌다(Byrne \& Noble, 1998; Byrne et al., 1992; Ham et al., 1999; Köbler \& Rosenhall, 2002). 그러나 현재 대부분의 보청기센터 등의 임상 현장에서는 방향 지각과 관련된 장비 및 설문지가 충분하지 않아서 난청인의 방향 지각 평가에 있어서 어려움을 겪는다.

$\mathrm{APHAB}$ 는 보청기 착용 전후의 심리음향적인 이득 또는 핸 디캡의 변화의 측정을 목적으로 국내에서 번역하여 사용하고
있다. 그러나 APHAB는 국내의 실정에 맞추어 다양한 번역본 이 임상에서 사용되고 있으나, 번역한 설문에 대한 검증이 되 지 않았다. 이에 본 연구에서는 Cox \& Alexander(1995)가 개 발한 $\mathrm{APHAB}$ 의 설문을 한국 실정에 맞게 구성하고자 하였다. 또한 상기에서도 언급하였듯이 난청인의 방향지각 능력을 평 가하기 위해서 Localization (LC)에 대한 항목을 추가하여 한 국 난청인의 보청기 착용 전후 심리음향적인 이득과 다양한 상 황에서의 의사소통 능력의 변화를 평가하는 데 활용할 수 있 도록 한국어판 보청기이득평가(Korean Version of Profile of Hearing Aid Benefit, K-PHAB) 설문지를 개발하고자 하였다.

\section{MATERIALS AND METHODS}

\section{연구 대상}

\section{설문의 선정}

본 연구는 한림국제대학원대학교 생명윤리위원회의 심사를 마친 후 진행하였다(심의번호: HUGSAUD459731). 문항의 선 정을 위한 설문의 수집은 부산, 서울 및 인천 등 총 5 곳의 보청 기센터에서 실시하였다. 설문에는 보청기의 착용 여부와 관계 없이 평균 연령이 65.7세(연령범위; 16 90세)인 대상자가 참여 하였다. 대상자는 총 141 명으로 일측 보청기 착용자는 61 명, 양 측 보청기 착용자는 63 명 그리고 미착용자는 17 명이었으며, 대 상자의 순음 기도청력역치의 평균과 표준편차는 Table 1 , 난청 정도에 따른 대상자의 분포에 대해서는 Table 2에 나타내었다.

\section{검사-재검사 신뢰도}

설문의 검사-재검사 신뢰도를 알아보기 위한 설문은 서울, 부산 등 총 2곳의 보청기센터에서 수집하였으며, 대상자는 보청 기 착용자 24명으로 평균 연령은 72.67세(연령범위; 54 86세)이 었다. 대상자는 Cox \& Gilmore(1990)가 사용한 방법을 참고하 여 보청기 착용 기간이 적어도 3 개월 이상이며, 보청기 착용 시 간이 하루에 4시간 이상인 난청인으로 하였다. 대상자의 순음

Table 1. Mean and SD of PTA for subjects $(n=141)$ who participated in the survey for selection of items

\begin{tabular}{lccccc}
\hline & \multicolumn{5}{c}{ Frequency $(\mathrm{Hz})$} \\
\cline { 2 - 6 } & 500 & 1,000 & 2,000 & 4,000 & PTA \\
\hline Right & & & & & \\
Mean & 58.5 & 63.7 & 67.3 & 72.6 & 63.3 \\
SD & 19.1 & 18.0 & 17.6 & 19.1 & 16.5 \\
Left & & & & & \\
Mean & 57.7 & 63.2 & 66.5 & 73.5 & 62.5 \\
SD & 20.0 & 17.5 & 14.8 & 16.9 & 15.8 \\
\hline
\end{tabular}

PTA: Pure tone threshold average of hearing threshold level of 500, 1,000 , and $2,000 \mathrm{~Hz}$, SD: standard deviation 
Table 2. Distribution of subjects based on PTA of the subjects $(n=$ 141)

\begin{tabular}{lcc}
\hline \multicolumn{1}{c}{ Degree of hearing loss } & Right (\%) & Left (\%) \\
\hline No hearing loss (below 25 dB HL) & $0(0)$ & $2(1.4)$ \\
Mild hearing loss (26-40 dB HL) & $12(8.5)$ & $8(5.7)$ \\
Moderate hearing loss (41-55 dB HL) & $36(25.5)$ & $45(31.9)$ \\
Moderately severe hearing loss & $51(36.2)$ & $46(32.6)$ \\
$\quad(56-70$ dB HL) & & \\
Severe hearing loss (71-90 dB HL) & $29(20.6)$ & $31(22.0)$ \\
Profound hearing loss (above 91 dB HL) & $13(9.2)$ & $9(6.4)$ \\
Total & $141(100)$ & $141(100)$ \\
\hline
\end{tabular}

PTA: pure tone average hearing threshold level of 500, 1,000, and $2,000 \mathrm{~Hz}$

Table 3. Mean and SD of PTA for subjects $(n=24)$ who participated in the questionnaire survey for reliability of test-retest

\begin{tabular}{lccccc}
\hline & \multicolumn{5}{c}{ Frequency $(\mathrm{Hz})$} \\
\cline { 2 - 6 } & 500 & 1,000 & 2,000 & 4,000 & PTA \\
\hline Right & & & & & \\
Mean & 57.5 & 63.96 & 66.25 & 69.79 & 62.57 \\
SD & 20.48 & 19.39 & 18.55 & 17.29 & 18.33 \\
Left & & & & & \\
Mean & 56.67 & 65.42 & 68.96 & 76.04 & 63.68 \\
SD & 15.01 & 13.51 & 12.16 & 17.69 & 11.55 \\
\hline
\end{tabular}

PTA: pure tone average of hearing threshold level of 500, 1,000, and $2,000 \mathrm{~Hz}, \mathrm{SD}$ : standard deviation

기도청력역치의 평균과 표준편차는 Table 3 과 같다.

\section{연구 장비}

설문 대상자의 선정을 위해 사용한 청력검사기는 설문 선정 시 MA 52 (MAICO, Eden Prairie, MN, USA), UNITY 2 (Siemens, Munich, Germany), GSI Audiostar pro (Grason-Stadler, Eden Prairie, MN, USA), 검사-재검사 시 MA 52 (MAICO), UNITY 2 (Siemens)였으며, 헤드폰은 모두 TDH-39 (Telephonics, Farmingdale, IL, USA)였다.

\section{연구 절차}

$\mathrm{K}-\mathrm{PHAB}$ 개발을 위한 연구절차는 1) 설문 문항의 개발 및 수집, 2) 문항의 국문학적 검증, 3) 문항의 선정, 4) 검사 및 재검 사 신뢰도 확인의 순으로 진행하였다.

\section{설문 문항의 개발 및 수집}

본 설문지에 포함된 항목은 총 5개로 APHAB (Cox \& Alexander, 1995)에서 사용한 $\mathrm{EC}, \mathrm{BN}, \mathrm{RV}, \mathrm{AV}$ 외에 $\mathrm{LC}$ 를 추가하 였으며, 각 항목에 대한 정의는 Table 4에 제시하였다. 설문 문 항의 개발과 수집은 기존의 관련 연구(Cox \& Alexander, 1995)와 임상에서 상담 시 난청인이 불편함을 언급하였던 상황 을 참고하여 구성하였으며, 설문은 항목당 7개로 총 35개의 문
Table 4. Definition of each category in K-PHAB

\begin{tabular}{cc}
\hline Categories & \multicolumn{1}{c}{ Definition } \\
\hline EC & $\begin{array}{c}\text { Communication under relatively easy listening } \\
\text { conditions }\end{array}$ \\
BN & $\begin{array}{c}\text { Speech understanding in the presence of multitalker } \\
\text { babble or other environmental competing noise }\end{array}$ \\
RV & $\begin{array}{c}\text { Speech understanding in moderately reverberant } \\
\text { rooms }\end{array}$ \\
AV & $\begin{array}{c}\text { Negative reactions to environmental sounds } \\
\text { LC }\end{array}$ \\
& $\begin{array}{c}\text { Ability to recognize the direction } \\
\text { of speech/environmental sound }\end{array}$ \\
\hline
\end{tabular}

EC: ease of communication, BN: background noise, RV: reverberation, AV: aversiveness of sounds, LC: localization, K-PHAB: Korean version of profile of hearing aid benefit

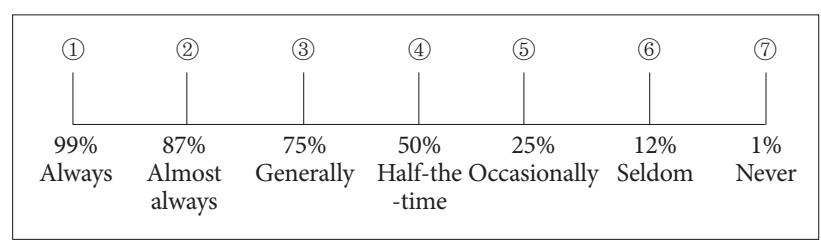

Figure 1. Assign a value for each answer.

항이었다. 반응의 척도는 7단계로 '항상 그렇다(99\%), 대부분 그렇다 $(87 \%)$, 가끔 그렇다 $(75 \%)$, 보통이다 $(50 \%)$, 가끔 그렇지 않다(25\%), 대부분 그렇지 않다(12\%), 절대 그렇지 않다(1\%)'로 구성하였으며, 반응 시 이해가 쉽도록 시각적인 척도를 함께 제 시하였다(Figure 1). 그리고 설문 문항의 선정을 위해 사용한 35 개의 문항은 Appendix 1에 나타내었다.

\section{설문의 국문학적 검증}

각 항목에 대한 설문 문항과 반응척도를 구성 한 후 국어국 문학 전공자 4 인에게 본 설문의 내용을 전달하여 검토하게 하 였다. 검토자는 각 문항에 대하여 문법적 그리고 의미론적인 측면에서 자유롭게 검토하게 하였으며, 이 내용을 전달받아서 본 설문지의 문항을 최종적으로 수정하였다.

\section{문항의 선정}

국문학적 검증을 마친 문항 총 35 문항을 무작위로 배치하였 으며, 설문의 신뢰도를 확보하기 위해 10 개의 문항에서 역으로 답할 수 있도록 구성하였다. 순음 기도청력검사는 설문 실시 이 전에 진행하였으며, 설문은 자신이 문항을 직접 읽고 기록하는 방법(paper-pencil)과 검사자가 직접 질문하여 설문을 작성하 는 방법(face-to-face) 중 대상자의 설문 작성 능력을 고려하여 설문 방법을 결정하도록 하였다.

\section{검사-재검사 신뢰도 확인}

검사-재검사 신뢰도는 1차 검사를 실시한 후 2 3주가 지난 뒤 2차 재검사를 실시하였다. 검사-재검사는 대상자의 학습효 
과 줄이기 위해 1 차 검사 시에는 설문 문항을 무작위로 배치한 $\mathrm{K}-\mathrm{PHAB}$ Form A (Appendix 2), 2차 검사 시에는 내용은 같으 나 Form A의 문항을 Microsoft Co. (Seattle, WA, USA)의 Excell 상에서 무작위화하여 재배치한 K-PHAB Form B(Appendix 3)를 사용하여 진행하였다. 그리고 검사-재검사에서 사 용한 설문을 토대로 개인 별 K-PHAB 점수의 의미 있는 변화 를 확인하기 위해서 $95 \%$ 예측구간(prediction interval)을 알아 보았다.

\section{분석 방법}

본 연구에서 문항의 타당도 확인을 위해 요인분석(factor analysis)에서 주성분분석법(principal component method)과 배 리맥스(varimax) 회전을 이용하여 분석하였다. 문항의 신뢰도 는 크론바흐 알파(Cronbach's alpha)로 분석하였으며, 크론바 흐 알파 값이 0.7 이상이면 내적 일관성이 있는 것으로 판단하 였다. 검사-재검사 신뢰도 검증 시에는 피어슨 상관분석(Pearson's correlation coefficient)과 대응표본 $t$-검정(paired $t$-test) 을 시행하였다. $95 \%$ 예측구간은 D’haenens et al.(2008)과 Lee et al.(2015)의 연구에서 사용한 방법으로 측정의 표준오차 (standard error of the measurement, SEM)는 SDd $/ \sqrt{2}(\mathrm{SDd}=$ 검사-재검사 차이의 표준편차), $95 \%$ 예측구간은 $\pm 2 \mathrm{SEM}$ 을 적 용하여 구하였다. 본 연구에서 사용한 통계 프로그램은 SPSS (ver. 18.0, IBM Co., Chicago, IL, USA)이었다.

\section{RESULTS}

\section{문항의 선정}

\section{설문의 요인분석}

Kaiser-Meyer-Olkin (KMO) 측도가 0.852였으며, Bartlett의 구형성 검정 근사 카이제곱 값은 2578.121 $(p<0.01)$, 문항이 공통성 0.4 이상으로 추출되어 본 자료가 요인 분석에 적합한 자료임을 확인할 수 있었다. 주성분 분석 결과, 1 이상의 고유치 를 보이는 성분은 7 가지였으며, 누적 설명률은 $63.972 \%$ 였다. Table 5에서 요인 1은 총 12문항으로 'BN'과 'RV'항목의 문항 이 섞여서 나타나 요인 1 을 '의사소통이 어려운 상황’으로 명명 하였다. 요인 2는 총 6문항으로 'EC', 요인 3은 총 7문항으로 'AV', 요인 4는 총 5문항으로 'LC' 항목으로 구성되었다. 요인 5 는 'LC' 항목의 문항이 적은 수로 이루어졌으며, 요인 6은 'EC' 와 'RV' 항목의 문항이 하나씩 분포하였다. 요인 7은 화자가 마 이크를 사용하여 말하는 상황과 관련되며 단일 문항으로 구성 되었다.

\section{문항 선정}

설문 문항의 선정 방법은 첫째, 설문 시 대상자가 이해의 어 려움을 보이거나 해당 항목에서 전반적인 중복 또는 다른 의미 로 이해한 경우, 둘째, 요인분석 실시 시 문항이 해당 항목에 묶 이지 않으며 요인과 변수 사이의 상관관계를 나타내는 값인 요 인 적재량이 0.4 이하인 경우, 셋째, 크론바흐 알파 값이 0.7이 하인 경우의 문항을 제거하였다. 이러한 과정을 통해 최종적으 로 선정한 설문 문항의 항목은 ' $\mathrm{EC}, \mathrm{BN}, \mathrm{RV}, \mathrm{AV}, \mathrm{LC}$ 로 각 항 목 당 4 문항으로 총 20 문항으로 구성하였다. 선정된 문항의 기 술통계는 Appendix 4에 제시하였으며, 문항은 Appendix 2 (Form A)와 Appendix 3 (Form B)에 나타내었다.

\section{선정된 설문 문항의 타당도 및 신뢰도 분석}

선정한 설문 문항의 타당도 분석을 실시하기 전에 표본의 적 절성을 확인하기 위한 $\mathrm{KMO}$ 측도는 0.815 였으며, Bartlett의 구형 성 검정 근사 카이제곱 값은 $1,209.829(p<0.01)$, 모든 문항이 공통성 0.4 이상으로 추출되어 요인 분석에 적합함을 확인하였 다. 주성분 분석 시 1 이상의 고유치를 보이는 성분은 5 가지였 으나, 요인 5의 경우 명확한 속성이 없고, 문항의 수가 극히 적어 요인을 4개로 결정하였다. 4 개 요인의 누적 설명률은 $58.127 \%$ 로 나타났다. Table 6에서 요인 1은 문항 선정을 위한 설문에서 요 인분석의 결과와 동일하게 'BN'과 'RV'항목의 문항들이 뒤섞인 결과를 보였으며, 이는 의사소통 시 대부분 난청인이 어려워하 는 상황들로 이루어져 있으므로 요인 1을 '의사소통이 어려운 상황'으로 명명하였다. 요인 2는 'LC', 요인 3은 'EC', 요인 4는 'AV' 항목의 문항으로 구성되었다.

구성타당도가 확인된 전체 문항의 수정된 항목-전체 상관관 계에서 모든 문항이 0.445 에서 0.712 로 나타났으며, 크론바흐 알파 값은 0.877 로 높은 신뢰도를 나타냈다. 항목별 크론바흐 알파 값은 0.754 에서 0.813 으로 분포하였고, 모든 항목에서 신 뢰도를 저하시키는 문항이 없으므로 본 설문지의 문항과 관련 된 내적 일관성 신뢰도가 높은 것을 확인하였다(Table 7).

\section{검사-재검사 신뢰도와 $95 \%$ 예측구간}

\section{검사-재검사 신뢰도}

검사-재검사 평균점수에 대한 대응표본 $t$-검정을 실시한 결과 모든 항목에서 평균점수 간 유의한 차이를 보이지 않았다 $(p>$ 0.05). Table 8에서 항목별 상관계수는 RV 항목에서 0.82 으로 가장 낮았고, $\mathrm{AV}$ 항목에서 0.96 으로 가장 높은 상관계수를 보 였다. 종합적으로 모든 항목에서 높은 신뢰도를 가지는 것을 확인하였다. 
95\% 예측구간

Table 8에서 검사-재검사 평균점수의 차이의 표준편차에 근 거한 항목 별 $95 \%$ 예측구간은 $\mathrm{EC}, \mathrm{BN}, \mathrm{RV}, \mathrm{AV}, \mathrm{LC}$ 는 각 각각 $\pm 13.78, \pm 9.78, \pm 10.24, \pm 13.5, \pm 12$ 로 나타났다.

\section{DISCUSSIONS}

본 연구에서는 보청기적합 전후에 일상생활에서의 수행능력 을 측정하여 보청기로 인한 심리음향적인 이득 그리고 핸디캡 의 변화를 알아보기 위한 한국어판 보청기 이득평가용 설문지 인 $\mathrm{K}-\mathrm{PHAB}$ 를 개발하고자 하였다.

Table 5. Results of factor analysis of the 35 questions used for K-PHAB items selection in this study

\begin{tabular}{|c|c|c|c|c|c|c|c|}
\hline \multirow{2}{*}{ Items } & \multicolumn{7}{|c|}{ Factor } \\
\hline & 1 & 2 & 3 & 4 & 5 & 6 & 7 \\
\hline BN5 & 0.722 & 0.081 & 0.085 & 0.343 & -0.126 & -0.111 & -0.027 \\
\hline RV4 & 0.706 & 0.146 & 0.152 & 0.126 & 0.003 & -0.070 & 0.003 \\
\hline BN4 & 0.705 & 0.100 & -0.059 & -0.024 & 0.443 & 0.119 & -0.102 \\
\hline RV6 & 0.691 & 0.123 & 0.037 & 0.385 & -0.015 & -0.058 & 0.026 \\
\hline BN2 & 0.686 & 0.165 & 0.117 & 0.184 & 0.089 & 0.033 & 0.012 \\
\hline RV1 & 0.673 & 0.210 & -0.059 & 0.164 & 0.042 & 0.125 & 0.408 \\
\hline BN7 & 0.638 & 0.132 & 0.133 & 0.115 & 0.143 & 0.015 & 0.467 \\
\hline RV2 & 0.618 & 0.142 & 0.069 & 0.306 & 0.114 & -0.107 & 0.110 \\
\hline BN6 & 0.596 & 0.082 & -0.047 & 0.059 & 0.541 & 0.075 & 0.091 \\
\hline BN1 & 0.591 & 0.197 & 0.042 & 0.102 & 0.121 & 0.003 & 0.477 \\
\hline RV7 & 0.582 & 0.043 & 0.048 & 0.055 & 0.372 & 0.075 & -0.337 \\
\hline $\mathrm{BN} 3$ & 0.575 & 0.038 & -0.040 & 0.064 & 0.301 & 0.365 & 0.053 \\
\hline EC5 & 0.230 & 0.760 & 0.199 & 0.134 & 0.091 & -0.036 & -0.001 \\
\hline EC2 & 0.081 & 0.741 & 0.100 & 0.137 & -0.076 & 0.022 & 0.267 \\
\hline EC6 & 0.088 & 0.722 & 0.110 & 0.146 & 0.012 & 0.177 & 0.250 \\
\hline EC7 & 0.253 & 0.712 & 0.006 & 0.173 & 0.061 & 0.090 & 0.009 \\
\hline $\mathrm{EC} 4$ & 0.062 & 0.691 & 0.016 & 0.160 & -0.023 & 0.055 & 0.061 \\
\hline EC3 & 0.148 & 0.690 & -0.014 & 0.014 & 0.321 & 0.163 & -0.292 \\
\hline AV5 & 0.118 & 0.101 & 0.822 & 0.056 & -0.047 & -0.070 & -0.045 \\
\hline AV6 & -0.012 & 0.107 & 0.788 & -0.108 & 0.064 & -0.213 & 0.006 \\
\hline AV2 & 0.109 & 0.008 & 0.772 & 0.052 & 0.082 & 0.150 & 0.028 \\
\hline AV3 & 0.270 & -0.094 & 0.706 & 0.211 & 0.069 & 0.157 & 0.003 \\
\hline AV4 & 0.022 & 0.195 & 0.704 & -0.072 & 0.153 & -0.368 & -0.004 \\
\hline AV1 & 0.048 & -0.082 & 0.680 & 0.276 & -0.182 & 0.269 & 0.083 \\
\hline AV7 & -0.287 & 0.344 & 0.666 & -0.004 & 0.047 & 0.045 & 0.187 \\
\hline LC5 & 0.218 & 0.195 & 0.129 & 0.779 & 0.049 & 0.068 & 0.040 \\
\hline $\mathrm{LC} 1$ & 0.324 & 0.121 & 0.049 & 0.655 & 0.089 & 0.184 & 0.104 \\
\hline LC3 & 0.171 & 0.193 & 0.116 & 0.652 & 0.183 & -0.050 & 0.161 \\
\hline LC4 & 0.253 & 0.312 & 0.026 & 0.624 & 0.124 & -0.177 & 0.022 \\
\hline LC2 & 0.309 & -0.031 & -0.125 & 0.577 & 0.504 & -0.105 & -0.161 \\
\hline LC6 & 0.089 & 0.012 & 0.169 & 0.098 & 0.760 & -0.037 & 0.252 \\
\hline LC7 & 0.132 & 0.108 & 0.041 & 0.224 & 0.635 & 0.016 & -0.043 \\
\hline EC1 & -0.089 & 0.285 & -0.001 & 0.013 & -0.009 & 0.702 & 0.103 \\
\hline RV5 & 0.178 & 0.502 & 0.034 & -0.141 & 0.053 & 0.547 & -0.121 \\
\hline RV3 & 0.219 & 0.379 & 0.119 & 0.221 & 0.159 & 0.124 & 0.530 \\
\hline Eigen value & 5.875 & 4.191 & 4.031 & 3.040 & 2.311 & 1.478 & 1.465 \\
\hline Explained variance (\%) & 16.784 & 11.973 & 11.517 & 8.685 & 6.604 & 4.223 & 4.186 \\
\hline Accumulative variance (\%) & 16.784 & 28.758 & 40.275 & 48.959 & 55.563 & 59.786 & 63.972 \\
\hline Number of items & 12 & 6 & 7 & 5 & 2 & 2 & 1 \\
\hline
\end{tabular}

$\mathrm{BN}$ : background noise, RV: reverberation, EC: ease of communication, AV: aversiveness of sounds, LC: localization, K-PHAB: Korean version of profile of hearing aid benefit 
Table 6. Results of factor analysis of 20 questions which were selected from the questionnaires

\begin{tabular}{|c|c|c|c|c|c|}
\hline \multirow{2}{*}{ Items } & \multicolumn{5}{|c|}{ Factor } \\
\hline & 1 & 2 & 3 & 4 & 5 \\
\hline RV1 & 0.804 & 0.165 & 0.222 & -0.066 & -0.151 \\
\hline $\mathrm{BN} 1$ & 0.757 & 0.095 & 0.216 & 0.050 & -0.079 \\
\hline RV6 & 0.671 & 0.422 & 0.068 & 0.036 & -0.001 \\
\hline $\mathrm{BN} 2$ & 0.662 & 0.197 & 0.096 & 0.211 & 0.195 \\
\hline $\mathrm{BN} 4$ & 0.644 & 0.076 & 0.043 & 0.034 & 0.625 \\
\hline RV4 & 0.640 & 0.200 & 0.115 & 0.152 & 0.068 \\
\hline $\mathrm{BN} 3$ & 0.617 & 0.075 & 0.054 & 0.012 & 0.351 \\
\hline RV2 & 0.586 & 0.376 & 0.064 & 0.126 & 0.159 \\
\hline LC5 & 0.206 & 0.768 & 0.183 & 0.159 & 0.001 \\
\hline $\mathrm{LC} 4$ & 0.182 & 0.724 & 0.310 & 0.027 & 0.055 \\
\hline $\mathrm{LC} 1$ & 0.333 & 0.688 & 0.124 & 0.094 & -0.120 \\
\hline LC2 & 0.236 & 0.674 & -0.106 & -0.021 & 0.489 \\
\hline EC2 & 0.167 & 0.098 & 0.799 & 0.075 & -0.117 \\
\hline $\mathrm{EC} 4$ & 0.127 & 0.143 & 0.741 & -0.023 & -0.126 \\
\hline EC5 & 0.196 & 0.168 & 0.741 & 0.232 & 0.190 \\
\hline EC3 & 0.101 & 0.095 & 0.663 & -0.035 & 0.456 \\
\hline AV2 & 0.069 & 0.029 & 0.058 & 0.813 & 0.007 \\
\hline AV3 & 0.265 & 0.149 & -0.081 & 0.759 & 0.021 \\
\hline AV4 & -0.083 & -0.039 & 0.228 & 0.704 & 0.176 \\
\hline AV1 & 0.094 & 0.173 & -0.002 & 0.696 & -0.399 \\
\hline Eigen value & 4.082 & 2.609 & 2.527 & 2.407 & 1.333 \\
\hline Explained variance (\%) & 20.410 & 13.046 & 12.636 & 12.034 & 6.664 \\
\hline Accumulative variance (\%) & 20.410 & 33.457 & 46.093 & 58.127 & 64.790 \\
\hline Number of items & 8 & 4 & 4 & 4 & 0 \\
\hline
\end{tabular}

RV: reverberation, BN: background noise, LC: localization, EC: ease of communication, AV: aversiveness of sounds

Table 7. Results of analysis of reliability for each item which were selected from the questionnaires

\begin{tabular}{ccccc}
\hline $\begin{array}{c}\text { Cate- } \\
\text { gories }\end{array}$ & $\begin{array}{c}\text { Item } \\
\text { number }\end{array}$ & $\begin{array}{c}\text { Corrected item- } \\
\text { total correlation }\end{array}$ & $\begin{array}{c}\text { Cronbach } \alpha \\
\text { if item deleted }\end{array}$ & $\alpha$ \\
\hline EC & 2 & 0.593 & 0.721 & 0.779 \\
& 3 & 0.537 & 0.753 & \\
& 4 & 0.553 & 0.746 & \\
& 5 & 0.677 & 0.675 & \\
BN & 1 & 0.562 & 0.749 & 0.785 \\
& 2 & 0.586 & 0.737 & \\
& 3 & 0.561 & 0.749 & \\
& 4 & 0.664 & 0.695 & \\
RV & 1 & 0.635 & 0.765 & 0.813 \\
& 2 & 0.619 & 0.772 & \\
& 4 & 0.567 & 0.795 & \\
& 6 & 0.712 & 0.726 & \\
AV & 1 & 0.541 & 0.703 & 0.754 \\
& 2 & 0.634 & 0.650 & \\
& 3 & 0.592 & 0.676 & \\
& 4 & 0.445 & 0.753 & \\
LC & 1 & 0.600 & 0.735 & 0.789 \\
& 2 & 0.550 & 0.760 & \\
& 4 & 0.606 & 0.732 & \\
& 5 & 0.631 & 0.719 & \\
\hline
\end{tabular}

EC: ease of communication, BN: background noise, RV: reverberation, AV: aversiveness of sounds, LC: localization
설문 검사 도구를 제작할 때 그 도구가 측정하고자 하는 것 을 얼마나 정확하고 충실하게 측정하고 있는지 그리고 동일성 과 일관성이 있는지를 판단하여야 하며, 이러한 검증 과정은 필수적이며 중요한 부분이다. 본 연구에서는 $\mathrm{K}-\mathrm{PHAB}$ 를 개발 하기 위하여 설문 항목을 5 개로 구성하였으며, 설문 문항은 각 항목 당 7 개로 총 35 개의 설문 문항을 마련하였다. 그리고 141 명에 대한 설문을 실시한 후 요인분석을 실시하여 ' $\mathrm{EC}, \mathrm{BN}$, $\mathrm{RV}, \mathrm{AV}, \mathrm{LC}$ ' 모든 항목에 대하여 각각 4 문항씩 총 20문항을 선정하였다. 문항의 선정 후 타당도 검증을 위하여 20문항으로 2차 요인분석을 실시한 결과 'BN', 'RV' 항목을 제외한 'EC', 'AV', 'LC' 항목은 각 3항목으로 분리되어 독립된 요인으로 구 성하였다. 또한 설문 문항 선정을 위한 요인분석을 실시했을 때 'BN', 'RV'의 항목이 중복되어 Cox \& Alexander(1995)의 연구 와 비슷한 결과를 나타냈다. 반향음이나 소음이 난청인의 어음 인지능력에 영향을 미친다는 Lee et al.(2008)와 Nabelek \& Pickett(1974)의 연구로 미루어 볼 때 배경소음이나 반향이 존 재하는 상황은 명확하게 서로 다른 상황이지만 난청인의 의사 소통에 영향을 주는 정도는 유사한 것으로 생각한다.

타당도를 검증하기 위해서 본 연구에서는 문항 내적 합치도 와 검사-재검사 신뢰도 과정을 진행하였다. K-PHAB의 문항 내 
Table 8. Reliability and $95 \%$ PI of test-retest in each category

\begin{tabular}{crccccc}
\hline Cate-gories & \multicolumn{1}{c}{ M1 } & M2 & Md & r $(p)$ & SEM & $95 \%$ PI \\
\hline EC & $29.44(19.56)$ & $28.97(15.97)$ & $0.47(9.75)$ & $0.87(<0.01)$ & 6.89 & \pm 13.78 \\
BN & $69.6(11.78)$ & $68.32(13.58)$ & $1.16(6.92)$ & $0.86(<0.01)$ & 4.89 & \pm 9.78 \\
RV & $72.20(12.20)$ & $74.41(11.81)$ & $-2.21(7.24)$ & $0.82(<0.01)$ & 5.12 & \pm 10.24 \\
AV & $23.45(21.25)$ & $22.69(18.46)$ & $0.76(9.55)$ & $0.96(<0.01)$ & 6.75 & \pm 13.50 \\
LC & $54.53(20.70)$ & $53.00(17.95)$ & $1.53(8.48)$ & $0.91(<0.01)$ & 6.00 & \pm 12.00 \\
\hline
\end{tabular}

M1: mean of K-PHAB scores at test, M2: mean of K-PHAB scores at retest, Md: mean of differences between K-PHAB scores at test and retest, r: Pearson's correlation coefficient. SEM: standard error of measurement, 95\% PI: 95\% prediction interval, K-PHAB: Korean version of profile of hearing aid benefit

적 합치도 분석 시 전체 문항의 크론바흐 알파값은 0.877 로 나타 나 높은 신뢰도를 보였으며, 항목별 신뢰도는 0.754 에서 0.813 으 로 나타났다. 그리고 24명에 대한 검사-재검사 신뢰도에서도 비교적 높은 상관계수를 보였다. 본 연구에서 참고한 Cox \& Alexander(1995)의 APHAB에서 항목 별 보청기 착용 전 내적 일관성 신뢰도를 살펴보면 0.82 에서 0.87 이었으며 항목 별 보청 기 착용 후 내적 일관성 신뢰도계수는 0.84 에서 0.85 로 어느 정 도 높은 신뢰도를 가지고 있었다. 또한 보청기 착용 전에 대한 항목별 검사-재검사 신뢰도 분석 결과는 0.65 에서 0.89 로 나타 났으며, 보청기 착용 후 에 대한 항목별 검사-재검사 신뢰도 분 석 결과는 0.67 에서 0.81 이었다. KHHIE (Ku \& Kim, 2000)연 구에서 크론바흐 알파의 신뢰도 계수는 0.9 이상으로 나타났으 며, 검사-재검사 신뢰도는 0.93 0.95로 높게 나타났다. 그리고 K-IOI-HA (Chu et al., 2012)연구에서는 0.8 이상의 신뢰도 를 확인할 수 있었다. 본 연구의 크론바흐 알파값을 다른 설 문지와 비교하여 볼 때 신뢰도 계수가 낮은 항목도 있었으나 George \& Mallery(2003)의 연구에서 $\alpha>0.9$ 이면 신뢰도 매 우 높음, $\alpha>0.8$ 이면 바람직함, $\alpha>0.7$ 이면 수용 가능하다고 정의하였음을 고려하여 볼 때 본 설문의 항목은 비교적 높은 신뢰도를 가지는 것으로 판단할 수 있다. 또한 검사-재검사 신 뢰도에서도 다른 설문지와의 비교 시 비교적 높은 상관계수를 보였으며, 항목별 $95 \%$ 예측구간을 확인하였으므로 이를 통해 개인 별 수행능력의 의미있는 점수의 변화를 확인할 수 있어 임상적인 설문도구로 유용하게 활용할 수 있을 것이다.

본 연구에서는 $\mathrm{APHAB}$ 를 근간으로 보청기 착용 전후의 심 리음향적인 이득과 핸디캡의 변화를 평가할 수 있는 한국어판 $\mathrm{K}-\mathrm{PHAB}$ 를 개발하여 체계적으로 검증하였다. 또한 $\mathrm{K}-\mathrm{PHAB}$ 는 $\mathrm{APHAB}$ 의 항목 외에 'LC' 항목을 추가하여 보청기 미착용, 일측 또는 양측 착용으로 인한 방향성을 평가할 수 있도록 하 였으며, 설문의 총 문항 수는 20개로 설문 시간을 절약할 수 있 도록 하였다. 따라서 $\mathrm{K}-\mathrm{PHAB}$ 는 보청기적합으로 인해 발생하 는 심리음향적 이득 또는 청능훈련 실시에 따른 효과의 평가에 유용하게 활용할 수 있을 것으로 생각한다. 그러나 본 연구에 서 개발한 $\mathrm{K}-\mathrm{PHAB}$ 는 성인 또는 노인을 설문의 대상하였기
때문에 향후에는 유소아 또는 아동을 대상으로 하는 $\mathrm{K}-$ $\mathrm{PHAB}$ 의 개발이 필요하다. 아울러 $\mathrm{K}-\mathrm{PHAB}$ 점수와 단어, 문 장 등 어음인지도와의 상관관계 등에 대한 연구가 필요하다.

중심 단어 : 보청기·보청기 이득·자가평설문지·APHAB· K-PHAB.

\section{Acknowledgments}

본 연구의 데이터 수집에 도움을 주신 스타키보청기 강동센터, 웨이브히어링 청각센터, 인천지멘스보청기, 황혜경보청기청각언어센 터에 감사드립니다.

\section{REFERENCES}

Bentler, R. A., Niebuhr, D. P., Getta, J. P., \& Anderson, C. V. (1993). Longitudinal study of hearing aid effectiveness. II: Subjective measures. Journal of Speech, Language, and Hearing Research, 36(4), 820-831.

Byrne, D. \& Noble, W. (1998). Optimizing sound localization with hearing aids. Trends in Amplification, 3(2), 51-73.

Byrne, D., Noble, W., \& LePage, B. (1992). Effects of long-term bilateral and unilateral fitting of different hearing aid types on the ability to locate sounds. Journal of the American Academy of Audiology, 3(6), 369-82.

Chang, Y. S., Choi, J., Park, G. Y., Youm, H. Y., Byun, H. Y., \& Cho, Y. S. (2014). Evaluation of satisfaction with hearing aids using a questionnaire based on MarkeTrak survey. Korean Journal of Otorhinolaryngol-Head and Neck Surgery, 57(5), 304-313.

Chu, H., Cho, Y. S., Park, S. N., Byun, J. Y., Shin, J. E., Han, G. C., et al. (2012). Standardization for a Korean adaptation of the international outcome inventory for hearing aids: Study of validity and reliability. Korean Journal of Otorhinolaryngol-Head and Neck Surgery, 55(1), 2025.

Cox, R. M. \& Alexander, G. C. (1992). Maturation of hearing aid benefit: Objective and subjective measurements. Ear and Hearing, 13(3), 131141.

Cox, R. M. \& Alexander, G. C. (1995). The abbreviated profile of hearing aid benefit. Ear and Hearing, 16(2), 176-186.

Cox, R. M. \& Alexander, G. C. (1999). Measuring satisfaction with amplification in daily life: The SADL scale. Ear and Hearing, 20(4), 306-319.

Cox, R. M., Alexander, G. C., \& Gray, G. A. (2003). Audiometric correlates of the unaided APHAB. Journal of the American Academy of Audiology, 14(7), 361-371.

Cox, R. M. \& Gilmore, C. (1990). Development of the profile of hearing aid performance (PHAP). Journal of Speech, Language, and Hearing Research, 33(2), 343-357.

Cox, R. M., Gilmore, C., \& Alexander, G. C. (1991). Comparison of two questionnaires for patient-assessed hearing aid benefit. Journal of the American Academy of Audiology, 2(3), 134-145.

D’haenens, W., Vinck, B. M., De Vel, E., Maes, L., Bockstael, A., Keppler, 
H., et al. (2008). Auditory steady-state responses in normal hearing adults: A test-retest reliability study. International Journal of Audiology, 47(8), 489-498.

Gatehouse, S. (1999). Glasgow hearing aid benefit profile: Derivation and validation of a client-centered outcome measure for hearing aid services. Journal of the American Academy of Audiology, 10, 80-103.

George, D. \& Mallery, P. (2003). SPSS for Windows Step by Step: A Simple Guide and Reference. 11.0 update. (4th ed.). Boston, MA: Allyn and Bacon.

Goff, A. E. (2013). The Use of Hearing Aid Outcome Measures in the Audiologic Treatment of Older Adults. Columbus, OH: The Ohio State University Press.

Ham, H. S., Song, S. Y., \& Park, M. S. (1999). Sound localization in subjects with a unilateral hearing loss according to hearing loss. Korean Journal of Otolaryngology-Head and Neck Surgery, 42(8), 961-966.

Köbler, S. \& Rosenhall, U. (2002). Horizontal localization and speech intelligibility with bilateral and unilateral hearing aid amplification. International Journal of Audiology, 41(7), 395-400.

Ku, H. \& Kim, J. (2000). Test-retest reliability of the Korean Hearing Handicap Inventory for the Elderly (KHHIE). Communication Sciences and Disorders, 5(1), 1-22.

Lee, J., Lee, K. W., Lee, J. H., Bahng, J., Kim, J., Choi, C. H., et al. (2015). Testretest reliability of sentence recognition score using Korean Standard
Sentence Lists for Adults (KS-SL-A). Audiology, 11(1), 17-25.

Lee, S. \& Lim, D. (2008). Effects of noise bands, signal to noise ratios, and source directions on monosyllabic word recognition in normal and hearing-impaired adult subjects. Audiology, 4(1), 52-57.

Lee, S. B., Koo, S. M., \& Lim, D. (2008). Effects of reverberation times and signal to noise ratios on discrimination of monosyllabic words in normal young and hearing-impaired elderly subjects. Audiology, 4(1), 16-23.

Nabelek, A. K. \& Pickett, J. M. (1974). Monaural and binaural speech perception through hearing aids under noise and reverberation with normal and hearing-impaired listeners. Journal of Speech, Language, and Hearing Research, 17(4), 724-739.

Noble, W., Ter-Horst, K., \& Byrne, D. (1995). Disabilities and handicaps associated with impaired auditory localization. Journal of the American Academy of Audiology, 6(2), 129-140.

Vestergaard, M. D. (2006). Self-report outcome in new hearing-aid users: Longitudinal trends and relationships between subjective measures of benefit and satisfaction. International Journal of Audiology, 45(7), 382-392.

Walden, B. E., Demorest, M. E., \& Hepler, E. L. (1984). Self-report approach to assessing benefit derived from amplification. Journal of Speech, Language, and Hearing Research, 27(1), 49-56. 


\section{APPENDIX}

Appendix 1. 35 questions which were used to select items in questionnaire survey

\begin{tabular}{|c|c|}
\hline Categories & Items \\
\hline \multirow[t]{7}{*}{ EC } & 1. 집에서 가족 중 한 사람과 대화할 때 그 사람의 말을 이해할 수 있다. $(\mathrm{R})^{*}$ \\
\hline & 2. 조용한 곳에서 마주 앉아 이야기할 때 그 사람의 말을 알아듣기 어렵다. \\
\hline & 3. 조용한 곳에서 대화할 때 상대방의 말을 이해할 수 있다. (R) \\
\hline & 4. 조용한 곳에서 상대방이 불러주는 주소나 전화번호를 받아 적기 어렵다. \\
\hline & 5. 조용한 방에서 한 사람과 대화할 때 자주 되물어야 한다.* \\
\hline & 6. 좁은 공간에서 상담할 때 상대방의 말을 알아듣기 어렵다. \\
\hline & 7. 친구와 조용하게 대화할 때 상대방의 말을 놓치곤 한다.* \\
\hline \multirow[t]{7}{*}{$\mathrm{BN}$} & 1. 사람이 많은 식당에서 종업원의 말을 이해하기 어렵다. \\
\hline & 2. 달리는 자동차 또는 전철 안에서 다른 사람의 말을 이해하기 어렵다. \\
\hline & 3. 혼잡한 상점 또는 마트에서 점원이 하는 말을 이해할 수 있다. $(\mathrm{R})^{*}$ \\
\hline & 4. 교통이 혼잡한 곳에서 다른 사람의 말을 알아들을 수 있다. (R) \\
\hline & 5. 자동차 안에서 라디오로 뉴스를 들을 때 누군가 떠들면 뉴스를 알아듣기 어렵다.* \\
\hline & 6. 많은 사람이 있는 곳에서 한 사람과의 대화가 가능하다. $(\mathrm{R})^{*}$ \\
\hline & 7. 여러 사람과 식사할 때 한 사람과 대화하는 데 어려움이 있다.* \\
\hline \multirow[t]{7}{*}{ RV } & 1. 극장에서 영화를 볼 때 한국 배우의 말을 이해하기 어렵다.* \\
\hline & 2. 큰 강의실에서 강의를 들을 때 많은 내용을 놓치곤 한다.* \\
\hline & 3. 마이크를 사용하는 사람의 말을 알아듣기 어렵다. \\
\hline & 4. 큰 강당에서 대화할 때 상대방의 말을 알아듣기 위해서는 집중해야 한다. \\
\hline & 5. 엘리베이터에서 대화할 때 상대방의 말을 이해할 수 있다. (R) \\
\hline & 6. 예배, 강론 또는 설법 시 그 내용을 이해하기 어렵다.* \\
\hline & 7. 소리가 울리는 방에서 이야기할 때 상대방의 말을 이해할 수 있다. (R) \\
\hline \multirow[t]{7}{*}{ AV } & 1. 전철 또는 기차역에서 전동차 또는 기차가 통과하는 소리가 너무 커서 불편하다. \\
\hline & 2. 가까이서 지나가는 트럭 또는 오토바이의 소리가 너무 커서 불편하다. \\
\hline & 3. 비상 벨 소리같이 예기치 못한 큰 소리를 들으면 몹시 불편하다.* \\
\hline & 4. 종업원이 그릇, 수저 등을 탁자에 올려놓을 때 부딪치는 소리가 커서 불편하다. \\
\hline & 5. 교통이 혼잡한 거리에 있을 때 교통소음이 너무 커서 불편하다.* \\
\hline & 6. 설거지를 하거나 접시를 부딪쳤을 때 소리가 너무 커서 불편하다. \\
\hline & 7. 상자의 테이프를 떼거나 비닐 포장지를 뜯는 소리가 커서 불편하다. \\
\hline \multirow[t]{7}{*}{ LC } & 1. 누군가 나를 부를 때 그 사람을 찾기 위해서는 여러 번 두리번거려야 한다. \\
\hline & 2. 주변에서 어떤 소리가 들릴 때 소리가 나는 위치를 쉽게 알 수 있다. (R) \\
\hline & 3. 물건이 떨어졌을 때 소리만 듣고서는 어디로 떨어졌는지 알기 어렵다. \\
\hline & 4. 휴대 전화기의 벨 소리를 듣고서 전화기의 위치를 찾기가 어렵다. \\
\hline & 5. 사람이 많은 곳에서 누군가 이야기할 때 그 사람의 위치를 찾기 어렵다. \\
\hline & 6. 자동차의 경적소리를 들었을 때 차가 없는 곳으로 즉시 피할 수 있다. (R) \\
\hline & 7. 자동차가 다가오는 소리만 듣고서도 어느 쪽에서 오는지 알 수 있다. (R) \\
\hline
\end{tabular}

*items which were referred to APHAB. (R): reverse, EC: ease of communication, BN: background noise, RV: reverberation, AV: aversiveness of sounds, LC: localization 
Appendix 2. K-PHAB (Form A)

Korean Version-Profile of Hearing Aid Benefit (K-PHAB) Form A

성 명

생 년 월 일

성 별
날 짜

- 보청기 미착용

- 보청기 착용

아래 문항을 읽고 본인의 일상생활의 경험과 가장 유사하다고 생각되는 곳에 동그라미( () 표시해주십시오. 답변은 7 개로 나누어 져 있습니다. 예를 들어, 어떠한 문항에서 설명한 상황이 본인에게 $87 \%$ 정도로 유사하다고 생각한다면, (2) 대부분 그렇다 $87 \%)$ 에 동그라미(○)를 표시해주시면 됩니다. 만약 설명된 상황을 경험해 본 적이 없다면 비슷한 상황을 생각해보시고 답변해주십시오.

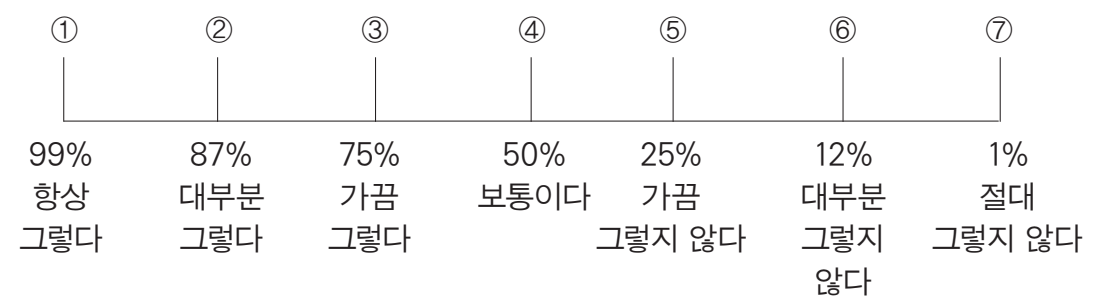

\begin{tabular}{|c|c|c|}
\hline 1 & 조용한 곳에서 마주 앉아 이야기할 때 그 사람의 말을 알아듣기 어렵다. & (1) (2) (3) (4) (5) (6) (7) \\
\hline 2 & 사람이 많은 식당에서 종업원의 말을 이해하기 어렵다. & (1) (2) (3) (4) (5) (6) (7) \\
\hline 3 & 종업원이 그릇, 수저 등을 탁자에 올려놓을 때 부딪치는 소리가 커서 불편하다. & (1) (2) (3) (4) (5) (6) (7) \\
\hline 4 & 조용한 곳에서 대화할 때 상대방의 말을 이해할 수 있다. & (1) (2) (3) (4) (5) (6) (7) \\
\hline 5 & 휴대 전화기의 벨 소리를 듣고서 전화기의 위치를 찾기가 어렵다. & (1) (2) (3) (4) (5) (6) (7) \\
\hline 6 & 주변에서 어떤 소리가 들릴 때 소리가 나는 위치를 쉽게 알 수 있다. & (1) (2) (3) (4) (5) (6) (7) \\
\hline 7 & 달리는 자동차 또는 전철 안에서 다른 사람의 말을 이해하기 어렵다. & (1) (2) (3) (4) (5) (6) (7) \\
\hline 8 & 가까이서 지나가는 트럭 또는 오토바이의 소리가 너무 커서 불편하다. & (1) (2) (3) (4) (5) (6) (7) \\
\hline 9 & 극장에서 영화를 볼 때 한국 배우의 말을 이해하기 어렵다. & (1) (2) (3) (4) (5) (6) (7) \\
\hline 10 & 조용한 곳에서 상대방이 불러주는 주소나 전화번호를 받아 적기 어렵다. & (1) (2) (3) (4) (5) (6) (7) \\
\hline 11 & 사람이 많은 곳에서 누군가 이야기할 때 그 사람의 위치를 찾기 어렵다. & (1) (2) (3) (4) (5) (6) (7) \\
\hline 12 & 전철 또는 기차역에서 전동차 또는 기차가 통과하는 소리가 너무 커서 불편하다. & (1) (2) (3) (4) (5) (6) (7) \\
\hline 13 & 조용한 방에서 한 사람과 대화할 때 자주 되물어야 한다. & (1) (2) (3) (4) (5) (6) (7) \\
\hline 14 & 큰 강의실에서 강의를 들을 때 많은 내용을 놓치곤 한다. & (1) (2) (3) (4) (5) (6) (7) \\
\hline 15 & 혼잡한 상점 또는 마트에서 점원이 하는 말을 이해할 수 있다. & (1) (2) (3) (4) (5) (6) (7) \\
\hline 16 & 누군가 나를 부를 때 그 사람을 찾기 위해서는 여러 번 두리번거려야 한다. & (1) (2) (3) (4) (5) (6) (7) \\
\hline 17 & 교통이 혼잡한 곳에서 다른 사람의 말을 알아들을 수 있다. & (1) (2) (3) (4) (5) (6) (7) \\
\hline 18 & 예배, 강론 또는 설법 시 그 내용을 이해하기 어렵다. & (1) (2) (3) (4) (5) (6) (7) \\
\hline 19 & 큰 강당에서 대화할 때 상대방의 말을 알아듣기 위해서는 집중해야 한다. & (1) (2) (3) (4) (5) (6) (7) \\
\hline 20 & 비상 벨 소리같이 예기치 못한 큰 소리를 들으면 몹시 불편하다. & (1) (2) (3) (4) (5) (6) (7) \\
\hline
\end{tabular}


Appendix 3. K-PHAB (Form B)

\section{Korean Version-Profile of Hearing Aid Benefit (K-PHAB) Form B}

성 명

생 년 월 일
성 별
날 짜

- 보청기 미착용

- 보청기 착용

아래 문항을 읽고 본인의 일상생활의 경험과 가장 유사하다고 생각되는 곳에 동그라미( $($ 표시해주십시오. 답변은 7 개로 나누어 져 있습니다. 예를 들어, 어떠한 문항에서 설명한 상황이 본인에게 87\% 정도로 유사하다고 생각한다면, (2) 대부분 그렇다 $87 \%$ ) 에 동그라미( $($ 를 표시해주시면 됩니다. 만약 설명된 상황을 경험해 본 적이 없다면 비슷한 상황을 생각해보시고 답변해주십시오

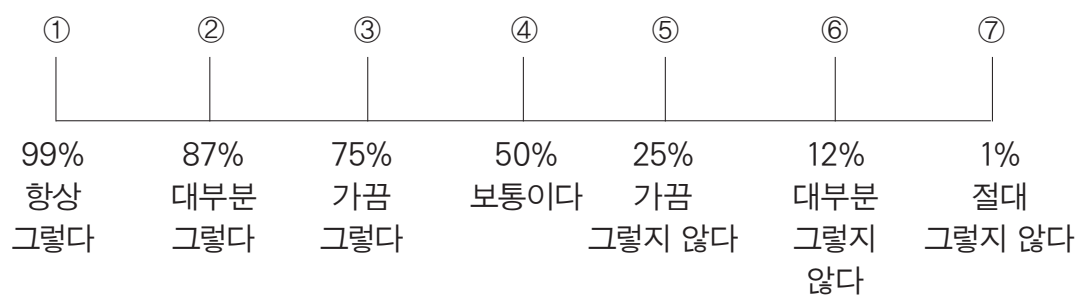

\begin{tabular}{|c|c|c|}
\hline 1 & 사람이 많은 식당에서 종업원의 말을 이해하기 어렵다. & (1) (2) (3) (4) (5) (6) (7) \\
\hline 2 & 극장에서 영화를 볼 때 한국 배우의 말을 이해하기 어렵다. & (1) (2) (3) (4) (5) (6) (7) \\
\hline 3 & 전철 또는 기차역에서 전동차 또는 기차가 통과하는 소리가 너무 커서 불편하다. & (1) (2) (3) (4) (5) (6) (7) \\
\hline 4 & 조용한 곳에서 마주 앉아 이야기할 때 그 사람의 말을 알아듣기 어렵다. & (1) (2) (3) (4) (5) (6) (7) \\
\hline 5 & 큰 강의실에서 강의를 들을 때 많은 내용을 놓치곤 한다. & (1) (2) (3) (4) (5) (6) (7) \\
\hline 6 & 조용한 방에서 한 사람과 대화할 때 자주 되물어야 한다. & (1) (2) (3) (4) (5) (6) (7) \\
\hline 7 & 누군가 나를 부를 때 그 사람을 찾기 위해서는 여러 번 두리번거려야 한다. & (1) (2) (3) (4) (5) (6) (7) \\
\hline 8 & 교통이 혼잡한 곳에서 다른 사람의 말을 알아들을 수 있다. & (1) (2) (3) (4) (5) (6) (7) \\
\hline 9 & 조용한 곳에서 상대방이 불러주는 주소나 전화번호를 받아 적기 어렵다. & (1) (2) (3) (4) (5) (6) (7) \\
\hline 10 & 휴대 전화기의 벨 소리를 듣고서 전화기의 위치를 찾기가 어렵다. & (1) (2) (3) (4) (5) (6) (7) \\
\hline 11 & 종업원이 그릇, 수저 등을 탁자에 올려놓을 때 부딪치는 소리가 커서 불편하다. & (1) (2) (3) (4) (5) (6) (7) \\
\hline 12 & 가까이서 지나가는 트럭 또는 오토바이의 소리가 너무 커서 불편하다. & (1) (2) (3) (4) (5) (6) (7) \\
\hline 13 & 달리는 자동차 또는 전철 안에서 다른 사람의 말을 이해하기 어렵다. & (1) (2) (3) (4) (5) (6) (7) \\
\hline 14 & 예배, 강론 또는 설법 시 그 내용을 이해하기 어렵다. & (1) (2) (3) (4) (5) (6) (7) \\
\hline 15 & 조용한 곳에서 대화할 때 상대방의 말을 이해할 수 있다. & (1) (2) (3) (4) (5) (6) (7) \\
\hline 16 & 비상 벨 소리같이 예기치 못한 큰 소리를 들으면 몹시 불편하다. & (1) (2) (3) (4) (5) (6) (7) \\
\hline 17 & 주변에서 어떤 소리가 들릴 때 소리가 나는 위치를 쉽게 알 수 있다. & (1) (2) (3) (4) (5) (6) (7) \\
\hline 18 & 큰 강당에서 대화할 때 상대방의 말을 알아듣기 위해서는 집중해야 한다. & (1) (2) (3) (4) (5) (6) (7) \\
\hline 19 & 혼잡한 상점 또는 마트에서 점원이 하는 말을 이해할 수 있다. & (1) (2) (3) (4) (5) (6) (7) \\
\hline 20 & 사람이 많은 곳에서 누군가 이야기할 때 그 사람의 위치를 찾기 어렵다. & (1) (2) (3) (4) (5) (6) (7) \\
\hline
\end{tabular}


Appendix 4. Means (Ms) and standard deviations (SDs) for each selected item in each category of K-PHAB

\begin{tabular}{|c|c|c|c|c|}
\hline \multirow{2}{*}{ Categories } & \multicolumn{4}{|c|}{ Items } \\
\hline & M & SD & M & SD \\
\hline \multicolumn{5}{|c|}{ Ease of communication (EC) } \\
\hline EC2 & 27.6 & 29.8 & 31.75 & 29.36 \\
\hline EC3 & 21.0 & 22.6 & & \\
\hline EC4 & 40.1 & 31.2 & & \\
\hline EC5 & 38.3 & 29.0 & & \\
\hline \multicolumn{5}{|l|}{ Background noise (BN) } \\
\hline BN1 & 58.1 & 30.9 & 55.94 & 30.77 \\
\hline BN2 & 64.1 & 28.7 & & \\
\hline BN3 & 48.6 & 30.9 & & \\
\hline BN4 & 52.9 & 30.7 & & \\
\hline \multicolumn{5}{|l|}{ Reverberation (RV) } \\
\hline $\mathrm{RV} 1$ & 56.9 & 29.8 & 67.7 & 28.71 \\
\hline $\mathrm{RV} 2$ & 71.0 & 26.3 & & \\
\hline RV4 & 75.1 & 27.5 & & \\
\hline RV6 & 67.8 & 28.3 & & \\
\hline \multicolumn{5}{|c|}{ Aversiveness of sounds (AV) } \\
\hline AV1 & 45.7 & 32.1 & 45.18 & 30.51 \\
\hline AV2 & 47.4 & 30.4 & & \\
\hline AV3 & 47.5 & 28.8 & & \\
\hline AV4 & 40.1 & 30.4 & & \\
\hline \multicolumn{5}{|l|}{ Localization (LC) } \\
\hline LC1 & 56.6 & 30.7 & 52.7 & 31.48 \\
\hline LC2 & 49.0 & 31.6 & & \\
\hline LC4 & 48.4 & 31.5 & & \\
\hline LC5 & 56.9 & 31.3 & & \\
\hline
\end{tabular}

K-PHAB: Korean version of profile of hearing aid benefit 